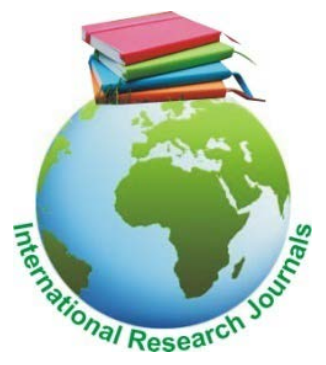

African Journal of Food Science and Technology (ISSN: 2141-5455) Vol. 9(2) pp. 12-18, July, 2018 DOI: http:/dx.doi.org/10.14303/ajfst.2018.229

Available online https://www.interesjournals.org/food-science-technology.html

Copyright (C2018 International Research Journals

\title{
Acidification process and properties of soft cheese made from cow milk using different starter cultures
}

\author{
Birhanu Bekele Hordofa*
}

Oromia Agricultural Research Institute, Yabello Pastoral and Dryland Agriculture Research Center, Yabello, Ethiopia.birhanubekel@gmail.com

\begin{abstract}
An experiment was conducted in Haramaya University Dairy Technology Laboratory to evaluate the effect of starter cultures on physicochemical, textures and consumer preference of soft cheese made from cow milk. Cow milk inoculated with cultures XPL-2 and CHN-22 resulted in slower acidification time than cow milk inoculated using cultures STI-12, RST-743 and R-707. Soft Cheese (SC) made using culture R-707 gave lower pH (4.52) and higher titratable acidity (1.04\%). Higher cheese yield (18.08\%), fat (18.48\%), protein (16.18\%), total solids (40.53\%) and ash $(2.73 \%)$ were obtained from cow milk SC made using culture STI-12. Instrumental analysis showed that SC of higher firmness $(5.50 \mathrm{~N})$ and brittleness (4.56) were obtained from cheese made using culture R-707, whereas higher $(-0.18 \mathrm{~N})$ adhesiveness was recorded from using culture XPL-2. Except color and appearance, consumer preference of taste, aroma and over all acceptance were significantly $(\mathrm{P}<0.05)$ affected by inoculation of cultures. In a conclusion, inoculations of commercial starter cultures influence the physicochemical, texture and consumer preference test of cow milk SC.
\end{abstract}

Keywords: Chemical composition, milk, preference test, starter culture, soft cheese, texture.

\section{INTRODUCTION}

Dairy product contains an important component of human diets (Seifu, 2013). Cheese is a dairy product produced and consumed all over the world, and plays an important role in human nutrition (Paula et al., 2012). In Ethiopia, milk is consumed either in fresh or fermented (sour) form. Cows' milk is the major produced and processed milk; however, milk from goats, sheep and camels is also consumed largely in the pastoral lowland areas of the country. The main dairy products produced and consumed in different parts of the country include fresh whole milk, sour milk (Ergo), butter, Arera (defatted sour milk) and a traditional cottage cheese (Ayib) and Metata made from butter milk (Yilma and Faye, 2006; Seifu, 2013).

Starter cultures are the major agents in producing fermented milk and dairy products. The use of starter cultures is an essential requirement in the manufacture of most cheeses (Cogan and Hill, 1993) and their major function is to produce lactic acid and in some cases, flavor compounds (Fox et al., 2000). They cause an acidification of milk at appropriate rate and time for cheese-making through the production of lactic acid, with the consequent decrease in $\mathrm{pH}$ and change the main milk components, thus affecting a number of aspects of cheese manufacturing process and finally cheese texture and composition (Bintsis and Papademas, 2002; Rupsiene, 2003; Kongo et al., 2013).

The rate of acidification milk for cheese production depends on the type of starter culture. This acid production rate is a critical in determining cheese properties and quality. Starter cultures affect the properties of the final product due to the variation in their meta-genomics properties (Kim, 2014). Therefore, understanding the effect of different starter cultures and characterizing the aspects of cheese manufacturing process and the finally cheese properties is a vital concept for further interventions to develop appropriate cheese products from cow milk. Thus, this research aimed to determine the acidification rate and properties of soft cheese made from cow milk using different starter cultures.

\section{MATERIALS AND METHODS}

\section{Materials}

Cow milk samples were collected from 5 cows of Haramaya University dairy farm and delivered to dairy technology laboratory of the university. The milk was cooled at $4 \pm$ $1^{\circ} \mathrm{C}$, immediately after milking until use. Recombinant 
camel chymosin (CHY-MAX®M 1000; EC 3.4 23.4) with a strength of 1000 International Milk Clotting Units (IMCU) $\mathrm{mL}^{-1}$ (Kappeler et al., 2006), Chr. Hansen A/S, Hørsholm, Denmark and commercial starter cultures were kindly donated by Chr. Hansen A/S, Hørsholm, Denmark. All analytical chemicals used were supplied by Haramaya University camel dairy project obtained from SigmaAldrich (Munich, Germany). Double distilled water was used for chymosin dilution.

\section{Milk Samples and Composition}

For all trials, a total of $50 \mathrm{~L}$ of cow milk were collected twice (25 $\mathrm{L}$ at ones) and physicochemical properties of cow milk ( $\mathrm{pH}$, titratable acid, total solids, ash, protein, lactose and fat) were analyzed. Protein, lactose, fat and total solids of raw milk were analyzed using FT1 technology use Milko-scan FT1 (Milko-scan ${ }^{\mathrm{TM}}$ FT1-FOSS, Hillerød, Denmark). The $\mathrm{pH}$ of milk was measured using calibrated electronic digital pH meter (Model Mettler Toledo MP220; Switzerland). The compositions of raw cow milk samples used in this experiment were $6.65 \pm 0.01(\mathrm{pH}), 0.13 \pm$ 0.01 (titratable acidity \%), $2.99 \pm 0.24$ (protein \%), $3.72 \pm$ 0.32 (fat\%), $12.22 \pm 0.70$ (total solid\%) and $0.85 \pm 0.02$ (ash\%).

\section{Cheese Making}

$25 \mathrm{~L}$ of cow milk was divided into five lit each and five trials of soft cheese-making were conducted using five different commercial starter cultures such as STI-12, RST-743, R-707, XPL-2 and CHN-22. Culture STI-12 is thermophilic homofermentative culture composed of strains of Streptococcus thermophilus, RST-743 is blended of thermophilic and mesophilic homofermentative culture composed of strains of Lactococcus lactis and Streptococcus thermophilus, R-707 is mesophilic homofermentative cultures composed of strains of Lactococcus lactis without biovar. Diacetylactis, XPL-2 is blended of thermophilic and mesophilic aromatic LD culture composed of strains of Lactococcus lactis subsp. cremoris, Lactococcus lactis subsp. lactis, Lactococcus lactis subsp. lactis biovar diacetylactis, Leuconostoc species, and Streptococcus thermophilus and CHN-22 is mesophilic aromatic LD culture containing strains of Lactococcus lactis subsp. cremoris, Leuconostoc pseudomesenteroides, Lactococcus lactis subsp. lactis biovar diacetylactis, Lactococcus lactis subsp. lactis, Leuconostoc mesenteroides (Berhe et al., 2015).

Cultures STI-12 and RST-743 were inoculated at $37^{\circ} \mathrm{C}$, whereas cultures R-707, XPL-2 and CHN-22 were inoculated at $30^{\circ} \mathrm{C}$ into cow milk separately. Each experiment was performed in two replications (two different sets of cheese were made). Whole milk was filtrated using muslin cloth, then each milk sample of treatment was pasteurized at $65^{\circ} \mathrm{C}$ for 30 min using a thermostatically controlled water bath (Model WNB 45, D-91126, Mannheim, Germany), and thermometer was used to check the temperature. For cooling, pasteurized milk was transferred to cold water in open plastic pan, adjusted to $37^{\circ} \mathrm{C}$ and $30^{\circ} \mathrm{C}$ inoculation temperature, and transferred to $10 \mathrm{~L}$ capacity of cheese vat (model Armfield Ltd., CAT REF FT 20-A 036106-001, Ringwood, Hampshire, UK) for curd making.

In the cheese vat, calcium chloride $(0.01 \mathrm{~g} / 5 \mathrm{~L}$ of milk) was added into the milk $30 \mathrm{~min}$ prior to the addition of the starter culture. Cooled milk was inoculated with starter culture according to each treatment of inoculation temperature. For inoculation of culture, one bag of commercial culture of $50 \mathrm{U}$ each was dissolved in $500 \mathrm{~mL}$ of fresh autoclaved $\left(121^{\circ} \mathrm{C}, 15 \mathrm{~min}\right)$ cow milk and then after the contents were completely dispersed, poured into small bottles and stored at $-20^{\circ} \mathrm{C}$ until use. Dissolved starter culture of 0.02 unit $/ 5 \mathrm{~L}$ was inoculated into milk.

Diluted (1:9 dilution of camel chymosin to double distilled water) liquid camel chymosin (CHY-MAX®M 1000, Christian Hansen, Denmark) with an activity of 85 IMCU/L at a concentration of $0.085 \mathrm{~mL} / \mathrm{L}$ was used to coagulate the milk and added into each treatment after about 30 min or more after inoculation of culture depending on attainment of $\mathrm{pH}$ value of $\approx 6.25$. The milk was allowed to coagulate for one hour after the addition of camel chymosin. The coagulated curd was cut and let to stand for $10 \mathrm{~min}$ and then was poured into a plastic mold lined with a cheese cloth, there after the whey was drained off from the curd. Finally, at the end of each manufacturing process, for more drainage time, the curd was placed in the mould for $24 \mathrm{~h}$ at room temperature. The cheese samples were collected in sterile containers and kept in refrigerator at $4 \pm 1^{\circ} \mathrm{C}$ for further analysis.

\section{Physicochemical Properties of Soft Cheese}

The physicochemical properties $(\mathrm{pH}$, titratable acidity, fat, protein, total solids and ash) of Soft Cheese (SC) were analyzed following standard procedures (AOAC, 1990). Cheese $\mathrm{pH}$ and titratable acidity were measured in the same day the cheese was manufactured. However, the other parameters were analyzed within $48 \mathrm{~h}$ of manufacture of the cheese.

\section{Cheese Yield}

The obtained cheese was weighed immediately prior to storage using a digital weighing balance. The weight of cheese sample was recorded, and the yield of the cheese was calculated as follow:

Cheese Yield\%=(weight of Cheese $) /($ weight of milk $) \times 100$

\section{Texture Analysis of Soft Cheese}

The cheese sample compression to analysis firmness, brittleness and adhesiveness were measured using micro 
stable texture analyzer (Model TA-XT Plus Stable Micro Systems Ltd, Vienna Court, Lammas Road, Godalming, and Surrey, UK. GU7 1YL). Cylindrical probe (P/25) with samples height $(h)=20.0 \mathrm{~mm}$ and diameter $(d)=18 \mathrm{~mm}$ was used for compression. First a $20 \mathrm{~mm}$ high layer cheese was cut with a blade and then cylindrical samples was slowly punched out vertically by a lubricated borer at $5^{\circ} \mathrm{C}$. The exterior of the cheese was not used and care was taken to keep the handling temperature below the test temperature. The cheese samples were conditioned at the measuring temperature, $13^{\circ} \mathrm{C}$, for at least $1 \mathrm{~h}$ before testing. Compression testing was performed with speed of $0.83 \mathrm{~mm} / \mathrm{s} .50 \mathrm{~kg}$ load cell was used. The upper and the lower compression plates, made of stainless steel, were lubricated with low-viscosity oil. The cheese samples were compressed to $50 \%$ of their original height (Wium et al., 1997). The characteristic of cheese texture samples; such as firmness (mean maximum positive force) brittleness (mean force at significant break in the curve on the first bite), and adhesiveness (mean maximum negative force) were extracted from compression test.

\section{Consumer Preference Test of Soft Cheese}

Consumer preference test like color, appearance, aroma, taste and overall acceptance were carried out with 12 trained sensory evaluators. The evaluation was identified using a 7-point hedonic scale (1=dislike extremely, 2=dislike moderately, 3=dislike slightly, 4=neither like nor dislike, 5=like slightly, 6=like moderately and 7=like extremely). Each experimental cheese sample was coded and provided to evaluators after $24 \mathrm{~h}$ of manufacturing. The evaluation was conducted independently and the evaluators rinsed their mouth by warm water and also had break for about $20 \mathrm{sec}$ between each testing. The evaluations of consumer preference test of all cheese were conducted on the same day (Hailu et al., 2014).

\section{Statistical Analysis}

Experimental design of physicochemical, textures and consumer preference test scored data were analyzed using the Analyzing of Variance (ANOVA) technique of Completely Randomized Design (CRD) with five treatments. All treatments' means were compared using student $F$ test at $\alpha=0.05$ levels and separated by Least Significant Difference method.

\section{RESULTS AND DISCUSSION}

\section{Acidification Process of Cow Milk}

Figure 1 indicates the acidification rate of different commercial starter cultures during soft cheese manufactured from cow milk. Result indicated that cow milk samples inoculated by cultures SIT-12 and RST-743 gave faster acidification time than cow milk inoculated with cultures XPL-2 and CHN-22. On the other hand, cow milk inoculated with cultures R-707 gave intermediate acidification time between cultures SIT-12 and RST-743; and XPL-2 and CHN-22.

The variation of these acidification time and $\mathrm{pH}$ values may be the inoculation of different starter cultures into cow milk that starter cultures have different acidification intensity. In cheese-making the rate of rapid acidification of milk through the production of lactic acid with the consequent decrease in $\mathrm{pH}$ depend on the type of starter cultures used (Kongo et al., 2013). Cow milk inoculated with all starter cultures under this experiment showed good firm curd properties and easily transferred from cheese vat to cheese mold. However, continuous whey separation was observed from cheese curd made using culture XPL-2 compared to others cultures used in this experiment with same condition of storage temperature time.

\section{Physicochemical Properties of Soft Cheese}

Physicochemical properties of cow milk soft cheese are summarized in Table 1 . The result showed that physicochemical properties of cow milk SC were significantly influenced by the addition of different

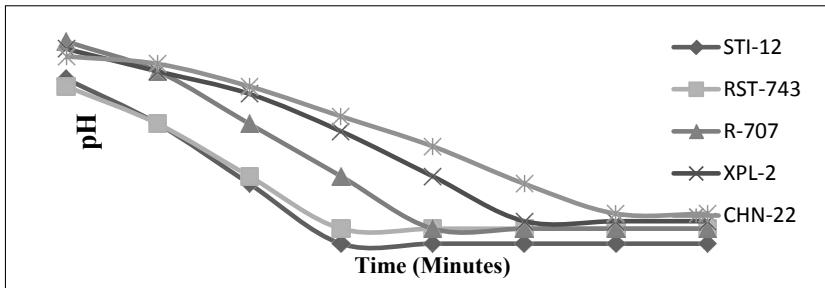

Figure 1. Acidification process of cow milk

STI-12 and RST-743 = Cow milk inoculated at $37^{\circ} \mathrm{C}$; R-707, XPL-2 and CHN-22 = Cow milk inculcated at $30^{\circ} \mathrm{C}$.

Table 1. Physicochemical properties of soft cheese made from cow milk

\begin{tabular}{|c|c|c|c|c|c|c|}
\hline \multirow[b]{2}{*}{ Parameters } & \multicolumn{5}{|c|}{ Values (Mean \pm SD) } & \multirow[b]{2}{*}{ P.V } \\
\hline & STI-12 & RST-743 & R-707 & XPL-2 & CHN-22 & \\
\hline pH & $4.62 \pm 0.01^{\mathrm{bc}}$ & $4.81 \pm 0.02^{\mathrm{ab}}$ & $4.52 \pm 0.16^{c}$ & $4.64 \pm 0.03^{\mathrm{bc}}$ & $4.95 \pm 0.04^{\mathrm{a}}$ & * \\
\hline Acidity (\%) & $0.95 \pm 0.01^{\mathrm{ab}}$ & $0.81 \pm 0.10^{\mathrm{bc}}$ & $1.04 \pm 0.07^{\mathrm{a}}$ & $0.96 \pm 0.01^{\mathrm{ab}}$ & $0.74 \pm 0.02^{c}$ & * \\
\hline Yield(Kg/100Kg) & $18.08 \pm 0.77^{a}$ & $16.23 \pm 0.81^{\mathrm{bc}}$ & $15.60 \pm 0.39^{c}$ & $17.59 \pm 0.12^{\mathrm{ab}}$ & $15.00 \pm 0.04^{c}$ & ** \\
\hline Fat $(\mathrm{g} / 100 \mathrm{~g})$ & $18.48 \pm 0.45^{a}$ & $17.65 \pm 0.15^{\mathrm{ab}}$ & $18.02 \pm 0.77^{a}$ & $16.40 \pm 0.36^{b c}$ & $15.84 \pm 0.65^{c}$ & * \\
\hline Protein $(\mathrm{g} / 100 \mathrm{~g})$ & $16.18 \pm 0.03^{a}$ & $13.17 \pm 0.07^{c}$ & $15.63 \pm 0.14^{a}$ & $13.41 \pm 0.28^{\mathrm{bc}}$ & $13.83 \pm 0.42^{b}$ & $* * *$ \\
\hline Ash (g/100g) & $2.73 \pm 0.17^{\mathrm{a}}$ & $1.80 \pm 0.03^{c}$ & $2.22 \pm 0.14^{b}$ & $2.39 \pm 0.02^{\mathrm{b}}$ & $2.20 \pm 0.10^{b}$ & ** \\
\hline
\end{tabular}


commercial starter cultures. Cow milk SC pH prepared using culture RST-743 is similar to the finding of Nazim et al. (2013) who gave a value of pH $4.82 \mathrm{SC}$ from cow milk. Soft cheese made using culture $\mathrm{CHN}-22$ had significantly $(\mathrm{P}<0.05)$ higher cow milk $\mathrm{SC} \mathrm{pH}$. However, there was no significance difference $(\mathrm{P}>0.05)$ among cow milk SC $\mathrm{pH}$ made using cultures STI-12, RST-743, R-707 and XPL-2.

Cow milk SC made using culture $\mathrm{CHN}-22$ gave lower $(P<0.02)$ titratable acidity. On the other hand, no significant difference $(P>0.05)$ of $S C$ titratable acidity was observed among cow milk SC made using cultures RST-743, R-707, XPL2 and CHN-22. Cheese yield of cow milk obtained from SC made using culture STI-12 was higher $(\mathrm{P}<0.01)$ than cow milk SC made using cultures R-707 and CHN-22. Cheese yield from cow milk recorded in this experiment using culture STI-12 is nearly in line with the result of Sant'Ana et al. (2013); Elsamani et al. (2014), who reported 19.40 and $19.5 \%$ cheese yield from cow milk fresh cheese and soft white cow milk cheese, respectively.

It was observed that cow milk SC made using cultures STI-12 and R-707 had significantly $(P<0.01)$ higher fat. Statistically, there was no significance difference $(P>0.05)$ among cow milk SC fat made using cultures STI-12, RST743 and R-707 and XPL-2. Fat of cow milk SC made using culture RST-743 is in agreement to the report of Sant'Ana et al. (2013) who reported $17.44 \%$ fat of cow milk fresh cheese. However, this result is extremely greater than the result of Elsamani et al. (2014) who reported 10.0\% fat of cow milk whit fresh cheese.

Cultures had significant effect on protein content of cow milk SC in which STI-12 and R-707 used for cheesemaking had significantly $(P<0.001)$ higher protein contents than that of cow milk SC made with cultures RST743 , XPL-2 and CHN-22. Soft cheese made from cow milk with culture R-707 in the present finding is in line with the report of Madruga et al. (2013) but greater than the finding of Sulejmani et al. (2014), who found 15.35 and $13.52 \%$ protein, respectively for cow milk soft cheese and Macedonian cheese made using commercial freeze dried culture curdling at $37^{\circ} \mathrm{C}$. On the other hand, the values of protein in SC made from cow milk using all cultures are to a great extent higher than the result of Elsamani et al. (2014) who reported $6.66 \%$ protein for white fresh cheese of cow milk.

Total solids were significantly higher $(P<0.01)$ in cow milk SC made with culture STI-12 than that of cow milk soft cheese made using cultures RST-743, R-707, XPL-2 and $\mathrm{CHN}-22$. On the other hand, no significant difference $(P>0.05)$ was observed among cow milk soft cheese total solids made using cultures RST-743, R-707, XPL-2 and $\mathrm{CHN}-22$. The values of total solids of cow milk soft cheese in this experiment made with cultures STI-12 and R-707 are lower than the result of Sant'Ana et al. (2013) who reported $44.03 \%$ of cow milk fresh cheese total solids.

Higher $(P<0.01)$ cow milk SC ash content was obtained from SC made using culture STI-12 than that of cow milk SC made using cultures RST-743, R-707, XPL-2 and CHN22. Cheese made using culture RST-743 had significantly lower $(\mathrm{P}<0.01)$ cow milk SC ash than that of cow milk SC prepared with cultures STI-12, R-707, XPL-2 and CHN-22. Ash values of cow milk SC in the current experiment made using cultures R-707, XPL-2, and CHN-22 are in line with the result of Sant'Ana et al. (2013) who reported 2.21\% ash of cow milk fresh cheese.

\section{Texture of Cow Milk Soft Cheese}

Figures 2-4 shows mean of firmness, brittleness and adhesiveness, respectively of soft cheese made from cow milk using different commercial starter cultures. The result explained that firmness, brittleness and adhesiveness of cow milk soft cheese were significantly $(P<0.05)$ different. Cow milk soft cheese made using culture R-707 gave significantly $(P<0.01)$ higher firm and brittle than cow milk soft cheese made using cultures STI-12, XPL-2 and CHN22. It was observed that cow milk SC made using culture
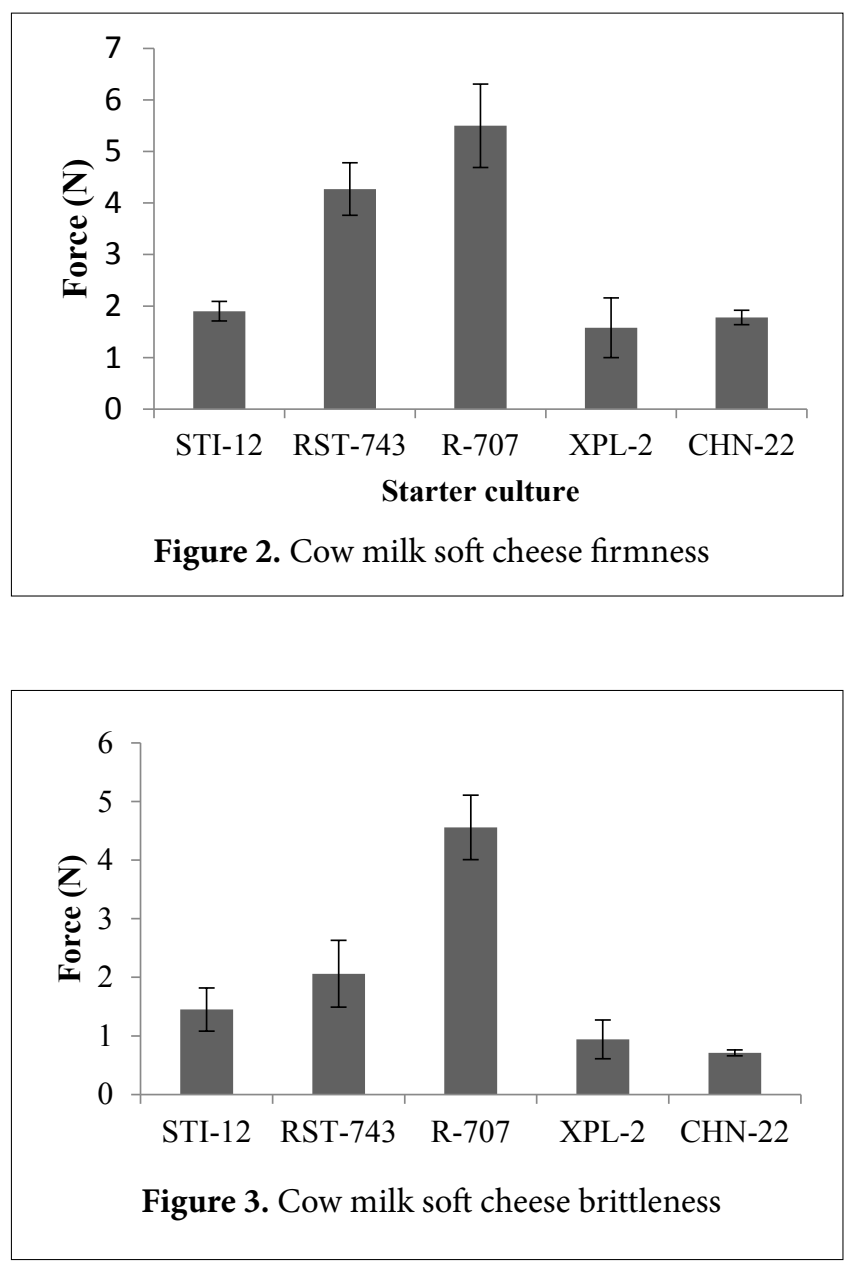


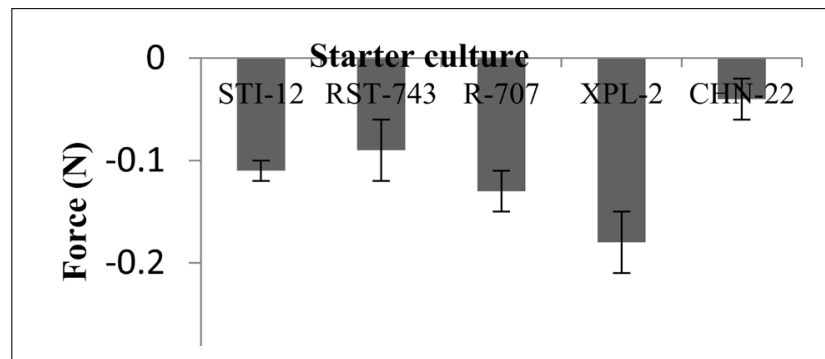

Figure 4. Cow milk soft cheese adhesiveness

CHN-22 had statistically higher negative force $(P<0.01)$, but had lower adhesive than that of cow milk soft cheese made using cultures STI-12, R-707 and XPL-2. However, cow milk soft cheese made using culture XPL-2 resulted in higher cheese adhesiveness. Cheese with lower negative force has higher adhesiveness than cheese with higher negative force.

The variations of cheese textures could be attributed to the moisture, protein and fat contents of the cheese samples. It was stated that moisture content of the cheese affects the textural characteristics of the cheese (Bongiolo et al., 2014). As indicated above, lower moisture contents of cheese samples showed higher resistance to deformation, however cow milk soft cheese made using culture STI-12 had lower moisture and higher protein content but showed less resistance to deformation than soft cheese made from cow milk using cultures R-707 and RST-743. This in which disagree with the report of Santos et al. (2013) and Bongiolo et al. (2014) who stated cheese samples with lower moisture contents showed higher texture values. However, in the present study, cow milk soft cheese made using culture R-707 had lower $\mathrm{pH}$ value that showed higher resistance to deformation than soft cow milk cheese samples made using cultures STI12, RST-743, XPL-2 and CHN-22.

The variations of soft cheese textures in present study may be due to the fact that during manufacture the moisture and calcium contents of cheese can alter the effect of $\mathrm{pH}$ on cheese texture. Higher moisture content cheese, at the same $\mathrm{pH}$ and salt content are less firm than their lower moisture content. This has been attributed to the extent of swelling of casein sub-micelles with the increase in caseinto-moisture ratio. Consequently, even small variations in moisture content can have significant effect on cheese texture of fresh cow milk cheese (Gunasekaran, 2003). In addition to these, Guinee et al. (2001) investigated the effect of fat content on cheese microstructure and texture. They explained that increases in fat content results in smoother and softer cheese, and increase in casein content results in firmer cheese. It was also found that higher fat and water content tends to weaken the protein structure of cheese (Fox et al., 2017).

\section{Consumer Preference Test of Cow Milk Soft Cheese}

Consumer preference test scores of cow milk soft cheese are indicated in Table 2. Except for color and appearance, significant differences $(P<0.001)$ of taste, aroma and over all acceptance were observed for consumer preference scores among cow milk soft cheese made using cultures STI-12, RST-743, R-707, XPL-2 and CHN-22. Cow milk soft cheese made using cultures XPL-2 and CHN-22 had higher scores for aroma and taste as compared to soft cheese made using cultures STI-12, RST-743 and R-707. Furthermore, cow milk soft cheese made using culture R-707 had higher scores for overall acceptance.

The variations in consumer preference test scored in this study mainly, in aroma, taste, and overall acceptance of the cheese samples might be attributed to the natural property of inculcated commercial starter cultures during acidification and curd making. Particularly, compounds such as CO2, diacetyl, and acetaldehyde are formed that give the development of distinct textural and flavor properties of the cheese from aromatic and non-aromatic starter cultures (Walstra et al., 2006; Papagianni, 2012).

\section{CONCLUSION}

Starter cultures used in this experiment showed a significant effect on soft cheese physicochemical, texture and consumer preference test. Cow milk treated with culture STI-12, RST-743 and R-707 for SC manufacture showed short acidification rate of time and gave better cheese compositional quality and texture. However, better consumer preference test scored of cow milk SC cheese taste and aroma were obtained from cheese made using cultures XPL-2 and CHN-22. The selection of starter culture for cheese manufacturing is based on the objective of producer and final product. Commercial starter cultures

Table 2. Consumer preference test scores of cow milk soft cheese

\begin{tabular}{|c|c|c|c|c|c|c|}
\hline \multirow[b]{2}{*}{ Parameters } & \multicolumn{5}{|c|}{ (Mean \pm SD) } & \multirow[b]{2}{*}{ P.V } \\
\hline & STI-12 & RST-743 & R-707 & XPL-2 & $\mathrm{CHN}-22$ & \\
\hline Color & $6.50 \pm 0.52$ & $6.25 \pm 0.75$ & $6.33 \pm 0.49$ & $6.08 \pm 0.51$ & $6.08 \pm 0.51$ & N.S \\
\hline Appearance & $6.16 \pm 0.71$ & $6.16 \pm 0.71$ & $6.16 \pm 0.71$ & $6.06 \pm 0.51$ & $6.33 \pm 0.49$ & N.S \\
\hline Aroma & $5.16 \pm 0.38^{b}$ & $5.08 \pm 0.51^{b}$ & $5.08 \pm 0.51^{b}$ & $6.25 \pm 0.62^{\mathrm{a}}$ & $6.08 \pm 0.28^{a}$ & $* * *$ \\
\hline Taste & $5.33 \pm 0.65^{b}$ & $5.41 \pm 0.51^{b}$ & $5.16 \pm 0.38^{b}$ & $6.41 \pm 0.51^{a}$ & $6.25 \pm 0.45^{\mathrm{a}}$ & $* * *$ \\
\hline $\begin{array}{c}\text { Overall } \\
\text { acceptance }\end{array}$ & $5.83 \pm 0.38^{b}$ & $5.66 \pm 0.65^{b}$ & $6.41 \pm 0.51^{a}$ & $5.08 \pm 0.79^{c}$ & $4.66 \pm 0.49^{c}$ & *** \\
\hline
\end{tabular}


STI-12, RST-743 and R-707 are better for acidification time, curd firmness and texture of soft cheese, whereas cultures XPL-2 and CHN-22 are preferable for consumer taste and aroma to manufacture cow milk soft cheese.

\section{ACKNOWLEDGEMENT}

The author would like to thank the Danish Development Agency (DANIDA) for financial support via Haramaya Camel Dairy Project.

\section{REFERENCES}

AOAC (1990). Official Methods of Analysis of the Association of Official Analytical Chemists. In: Kenneth Helrich(15 eds), Arlington, Virginia, USA.

Berhe T, Ipsen R, Seifu E, Kurtu MY, Eshetu M, Hansen $\mathrm{EB}$, (2015). Comparison of the acidification activities of commercial starter cultures on camel and cow milk. Poster session presented at $9^{\text {th }}$ NIZO Dairy Conference, Papendal, Netherlands.

Bintsis T, Papademas P (2002). Microbiological quality of white-brined cheeses: A review. In.t J. Dairy Technol. 55(3): 113-120.

Cogan TM, Hill C (1993). Cheese starter cultures: In cheese: chemistry, physics and microbiology. Chapman \& Hall, London, UK.

Delamare APL, de Andrade CCP, De Mandelli F, de Almeida RC, Echeverrigaray S (2012). Microbiological, physico-chemical and sensorial characteristics of Serrano, an artisanal Brazilian cheese. Food Nutr. Sci. 3(8): 1068-1075.

Elsamani MO, Habbani SS, Babiker EE, Ahmed IAM (2014). Biochemical microbial and sensory evaluation of white soft cheese. LWT-Food. Sci. Technol. 59(1): 553559.

Fox PF, Guinee TP, Cogan TM, Mcsweeney PLH (2000). Starter culture: In Fundamentals of cheese science, Aspen Publishers Inc, Gaithersburg, Maryland, USA.

Fox PF, Guinee TP, Cogan TM, Mscweeney PLH 2017). Cheese: Structure, rheology and texture. In: Fundamentals of Cheese Science. Springer, Boston, MA, USA.

Guinee TP, Feeney EP, Fox PF (2001). Effect of ripening temperature on low moisture Mozzarella cheese: 2 . Texture and functionality. Le Lait. 81(4): 475-485.

Gunasekaran S, Ak MM (2003). Cheese rheology and texture. CRC, Boca Raton, FL USA.

Hailu Y, SeifuE, Yilma Z 2014). Physicochemical properties and consumer acceptability of soft unripened cheese made from camel milk using crude extract of ginger (Zingiber officinale) as coagulant. Afr. J. Food. Sci. 8(2): 87-91.
Kappeler SR, van den Brik HJ, Rahbek-Nielsen H, Farah Z, Puhan Z, Hansen EB, Johansen E (2006). Characterization of recombinant camel chymosin reveals superior properties for the coagulation of bovine and camel milk. Biochem. Biophys. Res. Commun. 342(2): 647-654.

Kim W (2014).The genus Lactococcus: Lactic acid bacteria: Biodiversity and Taxonomy. In: Holzapfel WH, Wood BJB (Eds). John Wiley and Sons, Ltd.

Kongo JM (2013). Lactic acid bacteria as startercultures for cheese processing: Past, present and future development. INTECH Open science/open minds.

Magenis RB, Prudêncio ES, Fritzen-Freire CB, Stephan MP, do Egito AS, Daguer H (2014). Rheological, physicochemical and authenticity assessment of Minas Frescal cheese. Food Control. 45: 22-28.

Nazim MU, Mitra K, Rahman MM, Abdullah ATM, Parveen S (2013). Evaluation of the nutritional quality and microbiological analysis of newly developed soya cheese. Int. Food. Res. J. 20(6): 3373-3380.

Papagiannni M (2012). Metabolic engineering of lactic acid bacteria for the production of industrially important compounds. Comput. Struct. Biotechnol. J. 3: e201210003.

Rupsiene R (2003). Influence of leaven on dairy tanning and cheese quality. Food Chemistry and Technology, Conference Proceedings, Kaunas, Lithuania.

Sant'Ana AMS, Bezerril FF, Madruga MS, Batista AS, Magnani M, (2013). Nutritional and sensory characteristics of Minas fresh cheese made with goat milk, cow milk, or a mixture of both. J. Dairy. Sci. 96(12): 7442-7453.

Santos BNC, Silva CCCV, Domingues JR, Cortez MAS, Freitas DDGC, Chiappini CCJ, Araujo KGL (2013). Effect of calcium addition and $\mathrm{pH}$ on yield and texture of Minas curd cheese. Arq. Bras. Med. Vet. Zootec. 65(2): 601-609.

Seifu E (2013). Chemical composition and microbiological quality of Metata Ayib: A traditional Ethiopian fermented cottage cheese. Int. Food. Res. J. 20(1): 93-97.

Sulejmani E, Musliu ZH, Srbinovska S (2014). Influence of starter culture, temperature and processing technology on the quality of Macedonian white brined cheese. Biotechnol. Anim. Husb. 30(4): 579-588.

Walstra P, Wouters JTM, Geurts TJ (2006). Dairy Science and Technology $\left(2^{\text {nd }}\right.$ eds). Taylor and Francis Group, LLC. CRC Press Boca Raton, FL, USA. 
Wium H, Qvist KB, Gross M (1997). Uniaxial compression of uf-feta cheese related to sensory texture analysis. J. Texture Studies 28(4): 455-476.
Yilma Z, Faye B (2006). Handling and microbial load of cow's milk and irgo- fermented milk collected from different shops and producers in central highlands of Ethiopia. Eth. J. Anim. Prod. 6(2): 67-82. 